\title{
Desenvolvimento e Análise de Salame Colonial com Queijo e Ervas Finas
}

\author{
Sérgio A. Ullmann \& Cassandra M. T. Ribeiro
}

Com a tendência nas mudanças de hábito alimentar, os consumidores se tornaram mais exigentes, buscando alimentos mais saudáveis. O trabalho proposto é desenvolver a união de dois produtos (queijo e salame), adicionado de ervas finas, formulando um novo produto "salame colonial com queijo e ervas finas". Foram realizadas análises de cor e comparadas com uma amostra comercial. Os resultados da avaliação mostraramse dentro dos parâmetros de normalidade exigidos pela legislação vigente, qualificando o salame colonial como próprio para o consumo humano, resultando um produto com conteúdo proteico maior e com um teor de lipídeos menor.

Palavras Chave: qualidade; legislação; análises.

With the trend in eating habits change, consumers have become more demanding, seeking healthier foods. The proposed work is to develop the union of two products (cheese and salami) added herbs, formulating a new product "colonial salami with cheese and herbs." color analyzes were performed and compared with a commercial sample. The assessment results were within the normal parameters required by applicable law, describing the colonial salami as fit for human consumption, resulting in a product with higher protein content and lower fat contents.

Keywords: quality; legislation; test. 


\section{Introdução}

O processo de fabricação de embutidos fermentados e dessecados foi criado em torno do Mediterrâneo há séculos e, desde então, vem sendo aprimorado. A carne moída ou picada, temperada com sal e especiarias, seguida pela secagem em rolos, tornou o salame uma forma efetiva de preservar a carne (BACUS, 1984).

No Brasil, o consumo e a produção de salame estão concentrados principalmente na região Sul, tendo sua origem na colonização de imigrantes alemães e italianos, que encontraram um clima propício como aliado para a produção caseira, originando assim com o passar dos tempos pequenas fábricas de salame colonial. Sem números oficiais e devido a sua facilidade de fabricação, acredita-se que cerca de $50 \%$ do total da produção nacional seja de produção caseira (TERRA; FRIES; TERRA, 2004).

Denomina-se salame como um embutido cru, curado, fermentado, maturado e dessecado podendo ser defumado ou não. É um produto cárneo industrializado, obtido de carne suína e ou bovina, adicionado de toucinho, ingredientes e embutido em envoltórios naturais e/ou artificiais, sendo a presença de "mofos" característicos, considerada consequência natural do seu processo tecnológico de fabricação (BRASIL, 2000).

O queijo é uma das formas mais antigas para conservar o leite, a forma mais simples para definir o queijo é como um produto fresco ou maturado, feito pela coagulação natural do leite ou pela ação das enzimas específicas, e depois separada do soro. É considerado um dos alimentos mais antigos da história, começando há milhares de anos a.C., porém, em relação a sua descoberta, há várias hipóteses, quase todas relacionadas com o uso de recipientes de couro ou um recipiente feito de estômago de um animal, em que o leite era guardado e transportado. As enzimas presentes no couro ou no estômago provocaram acidentalmente a coagulação do leite (HOHENDORFF, C. G. 2006).

Para avaliar a qualidade do salame colonial acrescido de queijo e ervas finas, desenvolvidos no laboratório de alimentos do SENAI, Toledo, PR, foram necessárias análises microbiológicas e físico-químicas. O objetivo deste trabalho é desenvolver o salame e verificar as características físico-químicas, atestando a conformação com as exigências determinadas pelo Regulamento Técnico de Identidade e Qualidade para salames estabelecidos pela Instrução Normativa (IN) $n^{\circ}$ 22, de 31 de julho de 2000 do Ministério da Agricultura Pecuária e Abastecimento (MAPA). Além disso, avaliar se o salame desenvolvido atende às exigências microbiológicas, legisladas na Resolução da Diretoria Colegiada (RDC) $\mathrm{n}^{\circ} 12$ de 02 de janeiro de 2001 do Ministério da Saúde (MS).

A elaboração do salame com queijo e ervas finas visa oferecer ao consumidor um produto diferenciado e que atenda as suas necessidades, com uma porcentagem de proteína maior e uma porcentagem de lipídeos bem inferior, devido à substituição da gordura animal (toucinho) por queijo.

\section{Materiais e Métodos}

A elaboração e as análises do salame colonial com queijo e ervas finas foram realizadas pelo aluno, representante deste trabalho, nos laboratórios do SENAI, Toledo, Paraná, no período de fevereiro a agosto de 2015.

A elaboração do salame foi realizada seguindo as normas de boas práticas de fabricação (BPF) e os procedimentos regidos pela legislação, referentes a ingredientes obrigatórios, substituindo a gordura animal (toucinho) por queijo, elaborando um novo produto "salame colonial com queijo e ervas finas" e demais ingredientes, conforme tabela 1 .

Tabela 1: Formulação do salame tipo colonial com queijo e ervas finas

\begin{tabular}{|l|c|}
\hline Matéria-prima & Peso em gramas (g) \\
\hline Carne suína & 6.440 \\
\hline Carne bovina & 1.600 \\
\hline Queijo tipo caccio cavalo & 1.300 \\
\hline \multicolumn{2}{|c|}{ Ingredientes } \\
\hline Sal (cloreto de sódio) & 300 \\
\hline Nitrato e nitrito de sódio & 150 \\
\hline Alho em pó & 100 \\
\hline Eritorbato de sódio & 70 \\
\hline $\begin{array}{l}\text { Ervas finas (orégano, salsa, } \\
\text { alecrim, sálvia, manjericão, } \\
\text { tomilho) }\end{array}$ & 40 \\
\hline
\end{tabular}

Fonte: Adaptado de Terra (1998) 
O salame foi preparado, pesando-se a matéria-prima e demais ingredientes, moendo-se a carne suína e bovina em disco de $8 \mathrm{~mm}$, o queijo foi cortado manualmente em cubos pequenos. Na etapa seguinte, as matérias-primas e demais ingredientes foram colocados no misturador durante 30 minutos. Em seguida, deixado na câmara fria maturando por 24 horas em temperatura de 2 a 5 graus Celsius $\left({ }^{\circ} \mathrm{C}\right)$. Após isso, embutido em envoltório artificial de celulose, moldando-se as peças com $30 \mathrm{~cm}$ e colocando-as na câmara de maturação durante 30 dias, com temperatura inicial de $24^{\circ} \mathrm{C}$ e diminuindo gradativamente até $12^{\circ} \mathrm{C}$, segundo Terra (1998).

Os valores de umidade e cinzas foram determinados gravimetricamente, conforme método da AOAC (1990) Official Methods of Analysis, por aquecimento de estufa e mufla a $105^{\circ} \mathrm{C}$ e $600^{\circ} \mathrm{C}$ durante 6 horas, respectivamente. A análise de teor de proteína bruta foi baseada no processo semi-micro Kjeldahl, no qual se determina o nitrogênio contido na matéria orgânica, incluindo o nitrogênio proteico propriamente dito e outros compostos não proteicos, tais como: aminas, amidas, lecitinas e aminoácidos. Também conforme técnicas da AOAC (1990). Para extração dos lipídios totais, foi empregado o método de extração de gordura a quente, Gold Fish segundo Silva (1990). As análises físico-químicas de (Cinzas, Proteinas, lipídios e umidade) foram realizadas em duplicata no tempo zero e 30 dias. A análise de atividade de água foi realizada em triplicata, após a retirada do salame elaborado da câmara de maturação, conforme instruções descritas no medidor de atividade de água (Modelo:SN: S40001901; Marca DECAGON DEVICES,USA)

A medida de $\mathrm{pH}$ foi realizada em duplicata no tempo zero e, após trinta dias de fabricação, em aparelhos medidor de $\mathrm{pH}$ portátil, marca Marke MB-10P, modelo mPA. 210 P.

As análises microbiológicas de Coliformes termotolerantes, Stafilococos coagulase positiva, no tempo zero, Clostridium sulfito redutor e Salmonela sp após 30 dias da fabricação sendo feitas em duplicata por laboratório credenciado pelo MAPA. As análises da comparação de cor do salame elaborado, com uma amostra de salame colonial comercial foram realizadas na superfície das amostras cruas, tomando cinco pontos diferentes de leitura por amostra, utilizando o colorímetro Minolta CR400 (Minolta Corporation, Ramsay, NJ, USA) com esfera de integração e ângulo de visão de 450, ou seja, iluminação d/45 e iluminante
D e os valores de $\mathrm{L}^{*}$ (luminosidade), $\mathrm{a}^{*}$ (componente vermelho-verde), $\mathrm{b}^{*}$ (componente amarelo-azul) foram expressos no sistema de cor CIALAB (Commission International for Ilumination). $\mathrm{O}$ uso de * caracteriza os padrões determinados por esta Comissão. A análise de textura foi realizada no texturômetro, marca TA. HD. Plus texture analiser. As análises de cor e textura foram realizadas em triplicata, expressas como média e desvio padrão.

\section{Resultados e Discussão}

\section{ANÁLISES FÍSICO-QUÍMICAS}

Os resultados das análises físico-químicas com suas respectivas análises estatísticas e diferença entre médias e seus valores referentes, representadas na tabela 2 .

Tabela 2: Análise físico-química de salame tipo colonial com queijo e ervas finas, realizadas no tempo zero (amostra A) e após 30 dias de fabricação (amostra B)

\begin{tabular}{|c|c|c|c|}
\hline Análises & IN 22 & $\begin{array}{c}\text { Amostra A } \\
\text { (tempo zero) }\end{array}$ & $\begin{array}{c}\text { Amostra B } \\
\text { (30 dias) }\end{array}$ \\
\hline Cinzas \% & $\mathrm{NC}$ & $2,6147 \pm 0,08$ & $4,7119 \pm 0,41$ \\
\hline Proteína \% & $>18$ & $17,37 \pm 0,60$ & $24,32 \pm 0,23$ \\
\hline Lipídeos \% & $<30$ & $4,3695 \pm 0,82$ & $4,4519 \pm 0,56$ \\
\hline Umidade \% & $<70$ & $70,97 \pm 0,87$ & $64,87 \pm 0,47$ \\
\hline Aw & $<92$ & $\mathrm{NR}$ & 0,8322 \\
\hline $\mathrm{pH}$ & $<5,3$ & $5,40 \pm 0,00$ & $5,20 \pm 0,00$ \\
\hline Textura (kgf) & $\mathrm{NC}$ & $\mathrm{NR}$ & $3,58 \pm 0,30$ \\
\hline
\end{tabular}

IN: Instrução Normativa número 22 de 31 de julho de 2000 do Ministério da Agricultura e do Abastecimento; NC: Não Consta NR; Não Realizada. Fonte: Elaborada pelo autor (2015).

A legislação vigente não define um teor para a análise de cinza, mas o percentual médio dos resultados encontrados nas análises de cinza e seus respectivos desvios-padrão, encontrados no tempo zero (amostra A) foi de $(2,61 \pm 0,08)$ e após trinta dias de fabricação (amostra B) foi de $(4,71 \pm 0,41)$, foram considerados bem próximos aos teores encontrados por outros autores, como Santa (2008), comparando amostras de salames artesanais, encontrou teores de cinzas entre $3,76 \%$ a $8,84 \%$. Como demonstrado por Capeletto, Damo e Binko (2011), nas análises realizadas no desenvolvimento de linguiça toscana com queijo, obtiveram teores de cinza de 3,53\% a 7,00\%. Já os resultados encontrados em análise físico-química de salames coloniais, Silva et al., (2011) encontrou teores de cinza de $3,85 \%$ a $5,95 \%$. 
Os resultados obtidos neste trabalho para análise de proteínas foram satisfatórios, pois se apresentaram acima do mínimo exigido pela legislação brasileira, que é superior a $18 \%$ (BRASIL, 2000), com uma média de $(17,37 \pm 0,60)$ (amostra A) e $(24,32 \pm 0,23)$ (amostra B). Os teores de proteínas sofreram aumento devido à desidratação das peças. Macedo (2005) ressalta que a perda de água, devido à desidratação, promove a concentração dos demais componentes. Durante o processamento em seu trabalho, obteve salames com teores de proteínas entre $21,81 \%$ e $24,78 \%$ após 28 dias de processamento. Nas amostras de Silva et al., (2011), em análise físico-química de salames coloniais, encontrou teores de proteína entre 19,76\% a 28,52 \%. Para Stefanello et al., (2015), os teores de proteína encontrados variam entre $13,99 \%$ a $14,48 \%$, em efeito da adição de extrato de cogumelo do sol em linguiça suína e avaliação da estabilidade oxidativa e microbiológica do produto.

Para a análise de teores de lipídios, o resultado encontrado foi para a amostra A de $(4,36 \pm 0,82)$, e para a amostra B de $(4,45 \pm 0,56)$, estando em conformidade com a legislação vigente, que é menor que $18 \%$. Com a substituição da gordura animal (toucinho) por queijo, o resultado obtido foi um produto com um teor de lipídios reduzido e considerado satisfatório. Lima (2009) encontrou valores de lipídios variando de $13,62 \%$ a 13,51 \%, em elaboração e caracterização de salame de cordeiro Santa Inês. Em análise físicoquímica de salames coloniais, Silva et al. (2011) obteve valores variando entre 6,52 \% a 26,7\%. Para Santa (2008), comparando amostras de salames artesanais, encontraram-se teores variando entre $31,68 \%$ a $34,83 \%$, no final do processamento (14 dias).

Para a análise de umidade, os resultados encontrados para a amostra A $(70,97 \pm 0,87)$ e para amostra B $(64,87 \pm 0,47)$ estão de acordo com a IN 22. Este elevado teor de umidade proporciona textura macia aos salames coloniais, mas, por outro lado, valores maiores de umidade conferem maior susceptibilidade ao crescimento de micro-organismos. Seganfredo e Rodrigues (2013) encontraram teores de umidade de $62,50 \%$ a $67,50 \%$, em análises realizadas em elaboração de linguiça toscana com teor reduzido de sódio. Em análise físico-química de salames coloniais, Silva et al. (2011) obteve teores de umidade que variam entre $29.6 \%$ a $63,44 \%$. O conteúdo de umidade das amostras analisadas por Santa (2008), comparando amostras de salames artesanais variou de $20,97 \%$ a $55,11 \%$.

A atividade de água (aw) indica a quantidade de água disponível para as reações bioquímicas, físico-químicas e enzimáticas necessárias para o desenvolvimento de micro-organismos. A média encontrada na análise de aw, realizada em triplicata de um salame comercial e do salame elaborado aos trinta dias após fabricação foi idêntica de $(0,83 \%)$, estando em conformidade com a legislação IN 22, que é menor que $0,92 \%$. Para Lima (2009), o resultado encontrado foi de $0,91 \%$, em elaboração e caracterização de salame de cordeiro Santa Inês. Antoni (2005) avaliando salames tradicionais no mercado brasileiro elaborados com carne bovina e suína, encontrou valores que variaram de 0,89 a 0,91 . Amostras analisadas por Santa (2008), comparando amostras de salames artesanais a aw variou de $0,87 \%$ a 0,89\%. Degenhardt (2006), em sobrevivência de listeria monocytogenes em salame tipo italiano de baixa acidez, produzido sob condições brasileiras de fabricação, os valores de aw variaram de $0,88 \%$ a $0,89 \%$, após 28 dias de maturação.

Segundo Almeida (2005), o valor do $\mathrm{pH}$ da carne tem grande importância, uma vez que influencia na microbiota do produto, ajuda a classificar seu estado de conservação e é um importante fator para determinação da cor. Os valores de $\mathrm{pH}$ encontrados no salame elaborado para amostra $\mathrm{A}$ é de $(5,4 \pm 0,0)$, um pouco acima da legislação, mas não é consumido sem maturar e amostra B é de $(5,2 \pm 0,0)$ dentro da legislação que é menor que 5,3. Degenhardt (2006), em sobrevivência de listeria monocytogenes em salame tipo italiano de baixa acidez, produzido sob condições brasileiras de fabricação, obteve valores de pH variando de 5,10 a 5,19, após 28 dias de maturação. Cirolini et al., (2008), trabalhando com culturas startes nativas em salame italiano em comparação com culturas comerciais, encontraram valores finais de $\mathrm{pH}$ entre 4,87 e 5,48. Lima, (2009), encontrou valores de $\mathrm{pH}$ variando de 5,1 a 5,2, em elaboração e caracterização de salame de cordeiro Santa Inês.

A textura do salame foi determinada através do texturômetro, a média obtida em kgf para o salame elaborado foi de $(3,58 \pm 0,30)$, após 30 dias de fabricação, 
bem próximo dos valores obtidos por outros autores. Em estudos com carne suína e ovina, Reis e Soares (1998) elaboraram salames adicionados de glicose, ácido ascórbico e cultura de maturação em doses únicas e parceladas. Eles obtiveram para força de cisalhamento, valores entre 3,56 Kgf e 5,35 Kgf. Esses valores são semelhantes aos encontrados nessa pesquisa. Cavenaghi (1999) avaliando marcas de salame tipo italiano tradicional, encontrou valores entre 4,5 $\mathrm{Kgf}$ a $6,8 \mathrm{Kgf}$, para salame tipo italiano light 5,0 Kgf e para embutido fermentado obteve 3,4 Kgf.

\section{ANÁLISES DE COR}

A formação da cor em produtos cárneos processados, como embutidos fermentados, depende principalmente das modificações químicas do pigmento natural da carne, devido às suas reações com o cloreto de sódio refinado e com os sais de cura (nitrito). A cor constitui o primeiro impacto sobre o consumidor, despertando neste o desejo de consumir ou de rejeitar o produto, além de também fornecer uma indicação, embora nem sempre correta, sobre o grau de conservação do alimento. A cor é uma das características de qualidade da aparência dos alimentos de maior importância (CHAVES, 1980).

A cor dos produtos cárneos depende do teor de mioglobina presente na matéria-prima. Foram feitas análises em triplicata de (L, a, b, h), no salame elaborado e em uma amostra comercial. A média dos valores de $\mathrm{L}$, que indicam luminosidade, no salame elaborado, foi de 36,49 e na amostra comercial, de 40,29. Garcia, Gagleazzi e Sobral (2000) obtiveram valores de luminosidade de 36 , em salame tipo italiano após 20 dias de processamento. O valor de "a" que mede a intensidade de vermelho, a média obtida foi de 12,26, para o salame elaborado e de 15,75 e para amostra comercial. Cavenaghi e Oliveira (1999), trabalhando com várias marcas de salame tipo Italiano, encontraram valores que variaram de 11,6 a 15,5. Macedo (2005) obteve valores de 15,57 a 14,41 para variação da cor vermelha durante 28 dias de processamento. Os valores de "b" que avalia a intensidade de amarelo, a média do salame elaborado foi de 12,43 e para amostra comercial foi de 12,11. Estes valores estão próximos ao encontrados por Macedo (2005) que variou de 12,98 a 12,59 durante 28 dias de processamento. Para os valores de "h", que é a medida derivada (a e b), a média dos valores encontrados para o salame elaborado foi de 47,17 e para a amostra comercial foi de 37,55. Para Stefanello et al., (2015), em efeito da adição de extrato de cogumelo do sol em linguiça suína e avaliação da estabilidade oxidativa e microbiológica do produto, a média obtida foi de 41,77 após 28 dias de armazenamento.

\section{ANÁLISES MICROBIOLÓGICAS}

Todos os resultados encontrados nas análises microbiológicas realizadas estão dentro do padrão definido pela RDC $\mathrm{n}^{\circ} 12$, que estabelece o Regulamento Técnico dos Padrões Microbiológicos para carnes e produtos cárneos, indicando que o produto foi elaborado com matéria-prima de boa qualidade e procedência, em condições higiênico-sanitárias corretas, sem risco de consumo desse. As análises não realizadas (NR) no tempo zero devem-se ao produto não consumido imediatamente após a fabricação. E a não realizada aos trinta dias ocorre porque não apresentou contagens no tempo zero. Logo, a adição dos condimentos aliados ao tempo de maturação, contribuíram para aumentar a qualidade do produto final e dispensa a realização das análises.

Através das análises microbiológicas, são investigados micro-organismos indicadores que podem fornecer informações sobre a ocorrência de contaminação de origem fecal, provável presença de patógenos ou deteriorantes, além de indicar condições sanitárias inadequadas durante o processamento, produção ou armazenamento (SIQUEIRA, 1995).

\section{Conclusão}

A aceitação de novos produtos pelo mercado consumidor que busca praticidade, qualidade e segurança nos alimentos é um desafio e uma necessidade para as indústrias de alimentos na elaboração desses, seguindo as normas da legislação vigente. Os resultados obtidos neste trabalho demonstram que o salame colonial com queijo e ervas finas elaborado atendeu à legislação nos parâmetros tanto físico-químicos quanto microbiológicos, alcançando o objetivo proposto, apresentando um produto com teor maior para proteína e um teor menor para lipídeos, devido à substituição da gordura animal (toucinho) pelo queijo. 


\section{Referências}

1. Almeida, $\mathrm{C}$ de $\mathrm{O}$. Avaliação físico-química e microbiológica de linguiça toscana porcionada e armazenada em diferentes embalagens, sob condições de estocagem similares às praticas em supermercado. 150 f. Dissertação (Mestrado) - Universidade Estadual de Campinas, Campinas, 2005.

2. Antoni, I. Influência dos micro-organismos Staphylococcus xylosus, Lactobacillus plantarum e Staphylococcus carnosus no perfil aromático de salames de peru. Tese (doutorado) - Universidade Estadual de Campinas, Campinas, 2005.

3. Bacus, J. Utilization of Microorganisms in Meat Processing - A handbook for meat plant operators. Letchworth: Research Studies Press Ltd, 1984. In: DEGENHARDT,ROBERTO. sobrevivência de listeria monocytogenes em salame tipo italiano de baixa acidez, produzido sob condições brasileiras de fabricação. Dissertação (Mestrado), disponível em : <https://repositorio.ufsc.br/bitstream/ handle/123456789/89063/244637.pdf?sequence=1 $>$ Acesso em 16 fevereiro 2015.

4. Brasil. Ministério da Agricultura, Pecuária e do Abastecimento. Instrução Normativa n. 22, de 31 de julho de 2000. Diário Oficial [da] República Federativa do Brasil, Brasília, 03 de agosto, 2000.

5. CavenagHI, A. D.; OLIVEIRA, M. N. Influência de algumas características físico-químicas e sensoriais na qualidade do salame tipo italiano fabricado no Brasil. Revista Nacional da Carne, n. 263, p. 44-47, 1999.

6. Cavenaghi, A.D. Uso da associação de culturas starter na fabricação do salame tipo Italiano.. 151 p. Dissertação (Mestrado) - Faculdade de Ciências Farmacêuticas, Universidade de São Paulo, São Paulo, 1999.

7. Capeletto; E.; DAMO; J; C.; BINKO; K; T; C. Desenvolvimento de linguiça toscana com queijo, Trabalho de Conclusão do Curso (TCC) - Universidade Tecnológica Federal do Paraná, Medianeira, 2011.

8. Cirolini, A. Staphylococcus xylosus e lactococcus lactis ssp lactis nativos utilizados na elaboração de salame tipo italiano. Dissertação (Mestrado) - Universidade Federal de Santa Maria, Santa Maria, 2008.

9. Chaves, J.B.P. Controle de qualidade para a indústria de alimentos: princípios gerais. Viçosa: Universidade Federal de Viçosa, 1980. 18p. [Apostila].

10. Degenhardt, R. Sobrevivência de Listeria monocytogenes em salame tipo italiano de baixa acidez, produzido sob condições brasileiras de fabricação. 2006. Disponível em <http://repositorio.ufsc.br/>. Acesso em 15 de outubro 2015.

11. Garcia, F. T.; Gagleazzi, U. A.; Sobral, P. J. A. Variação das propriedades físicas e químicas do salame tipo italiano durante secagem e fermentação. Brazilian Journal of Food Technology, v. 3, p. 151-158, 2000.

12. , C. G. Produção de queijos, 2006. Disponível em: <http://www.ebah. com.br/content/ABAAAen2cAC/producao-queijo> Acesso em 15 março 2015.
13. Lima, I. A. Elaboração e caracterização de salame de cordeiro santa inês. Itapetinga, 76 f. Dissertação (Pós-graduação de mestrado) Universidade Estadual do Sudoeste da Bahia, Itapetinga, 2009.

14. Macedo, R. E. F. Utilização de culturas lácticas probióticas no processamento de produto cárneo fermentado. $193 \mathrm{f}$. Tese (Doutorado) - Universidade Federal do Paraná, Curitiba, 2005.

15. Reis, A. G. B.; Soares, G. J. D. Salame colonial processado com carne suína e ovina. Revista Brasileira de Agrociência, v.2, n.2, p.115-120, 1998.

16. Santa, O. R. D. Avaliação da qualidade de salames artesanais seleção de culturas starter para a produção de salame tipo italiano. Tese (Doutorado) - Universidade Federal do Paraná, Curitiba, 2008.

17. Seganfredo, D.; Rodrigues, S. Elaboração de linguiça toscana com teor reduzido de sódio. Trabalho de Conclusão do Curso (TCC) Universidade Tecnológica Federal do Paraná, Medianeira, 2013.

18. Silva, D. J. Análise de alimentos (Método químicos e biológicos). Viçosa, MG: Universidade 314 Federal de Viçosa, 1990. 165p.

19. Silva, C.; Savariz. F. C; Follmann, H. M.; Nuñez, L.; Chapla, V. M.; Silva, C. F. Análise físico-química de salames coloniais comercializados no município de Toledo, Estado do Paraná. Technology Acta Scientiarum, v. 33, n. 3, p. 331-336, 2011.

20. Siqueira, R.S. Manual de microbiologia de Alimentos. Brasília: EMBRAPA, 1995.

21. Stefanello, F. S.; Cavalheiro, C. P.; Ludtke, F.L., Silva, M. S.; Fries, L. L. M.; Kubota, E. K. Efeito da adição de extrato de cogumelo do sol em linguiça suína e avaliação da estabilidade oxidativa e microbiológica do produto. Ciências Agrárias, Londrina - PR, v.36, n.1, p.171-186, jan/fev. 2015. Disponível em: $<$ http://www.uel.br/ revistas/uel/index.php/semagrarias/article/view/16702/pdf_579>. Acesso em: 25 ago. 2015.

22. Terra, A. B. M.; FRIES, L. L. M.; TERRA, N. N. Particularidades na fabricação de salame. São Paulo: Varela, 2004. Disponível em: $<$ http://intranetdoc.epagri.sc.gov.br/producao_tecnico_cientifica/ DOC_31450.pdf $>$ Acesso em 15 março 2015.

23. Terra, N. N. Apontamentos de tecnologia de carnes. São Leopoldo. Editora, Unisinos. 216p. 1998

\section{Sérgio A. Ullmann \& Cassandra M. T. Ribeiro}

Faculdades da Indústria SENAI Toledo. Curso Superior de Tecnologia em Alimentos. Rua Júlio de Castilhos 3465. Vila Industrial. CEP 85904-175, Toledo,Paraná, Brasil.

E-mail: cassandra.ribeiro@pr.sanai.br 